\title{
Estudo eletropalatográfico das seqüências /s s/ e /s $/$ em português brasileiro
}

\author{
Electropalatographic study of /ss/ and /s $\int /$ sequences in \\ Brazilian Portuguese
}

César Reis

Universidade Federal de Minas Gerais

\begin{abstract}
This paper analyses coarticulation process that occurs when one voiceless alveolar fricative follows another alveolar voiceless fricative with a word boundary between them and when one alveolar voiceless fricative follows a voiceless post-alveolar fricative with also a word boundary between them. In order to do that, we utilized the electropalatographic and spectrographic techniques. The results indicate that, in the context/s \# s/, the sequence had the same acoustic and electropalatographic characteristics as the voiceless alveolar fricative in initial syllable position, but the sequence /s \# S/ presented different characteristics from both the voiceless alveolar fricative and the voiceless post-alveolar fricatives.
\end{abstract}

Keywords

Electropalatography, Coarticulation, Fricative.

\section{Resumo}

Este trabalho trata de processos de co-articulação da fricativa alveolar não vozeada seguida de outra fricativa alveolar não vozeada, em fronteira de palavra, e da fricativa alveolar não vozeada seguida de fricativa pós-alveolar não vozeada, também em fronteira de palavra. 
Para essa análise foram utilizadas imagens eletropalatográficas, o sinal sonoro, o espectrograma e o baricentro. Os resultados da análise mostraram que, no contexto /s \# s/, a seqüência consonantal apresenta as mesmas características acústicas e eletropalatográficas de uma fricativa alveolar em posição inicial de sílaba. Já a seqüência /s \# S/ apresenta características distintas da fricativa alveolar e da fricativa pós-alveolar

Palavras-chave

Eletropalatografia, Co-articulação, Fricativa 


\section{Introdução}

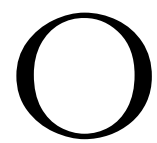

s sons da fala, que são comumente tratados como entidades estáticas e abstratas, como o som $t$, o som $a$, por exemplo, são eventos dinâmicos, se observados sob o ângulo da sua produção articulatória, ajustando-se constantemente às condições de produção dos sons da fala próximos que o precedem e o seguem. Todo som da fala tem um alvo ao qual se dirige. De onde parte para atingir esse alvo, como atinge o alvo e como se afasta do alvo são algumas das questões às quais procuramos dar respostas, quando nos interessamos em compreender o mecanismo de produção da fala.

O objetivo deste trabalho é a apresentação de uma técnica de descrição e análise dos movimentos articulatórios, a eletropalatografia ou EPG, que fornece informações detalhadas sobre os contatos língua-palato, ${ }^{1}$ (ESPESSER, 1996) além de apresentar os primeiros resultados de um estudo sobre os processos de co-produção, envolvendo as fricativas alveolares do português brasileiro (REIS; ESPESSER, 2006). Neste artigo, vamos examinar a fricativa alveolar não vozeada, seguida de outra fricativa alveolar não vozeada, em fronteira de palavra, /s \# s/, ou de uma fricativa pós-alveolar não vozeada, também em fronteira de palavra /s \# $\int /$.

Trataremos do som da fala [s], considerado particularmente complexo na sua produção (HARDCASTLE, 1976) e tendo criado dificuldade a teorias sobre a sílaba. Mobilizando normalmente todos os músculos intrínsecos da língua, vários músculos extrínsecos, além de músculos faciais na sua produção, apresenta uma concavidade no dorso da língua e um canal central na região da lâmina. Além disso, o gesto articulatório tem que fornecer ao fluxo de ar fonatório as condições apropriadas para o turbilhonamento do ar necessário à produção de um som fricativo.

\section{Representação fonológica e co-articulação}

Como a eletropalatografia é um dos recursos mais eficientes na identificação dos contatos da língua nas regiões alveolar, pós-alveolar e palatal, podendo, 
também, dar indicações sobre contatos na região velar, tem sido utilizada por vários pesquisadores interessados, sobretudo, nos processos de co-articulação ou de co-produção dos segmentos previstos por representações fonológicas diversas.

Nolan (1992) mostrou que as representações fonológicas para o processo conhecido como assimilação não explica o processo co-articulatório. Observando o comportamento da oclusiva alveolar não vozeada em expressões como late calls, com o auxílio da eletropalatografia, mostra que não se trata de uma assimilação de ponto, em que o ponto alveolar é substituído pelo ponto velar, mas que pode haver a seguinte gradação: alveolar, alveolar residual, alveolar zero e não alveolar. Conclui que, do ponto de vista da articulação, o processo é gradual, o que as representações fonológicas não podem revelar, uma vez que se baseiam em geral no segmento. Acrescenta que não se trata de fenômeno meramente fisiológico, mas de um contraste fonético subcontrastivo sob controle do locutor.

Holst and Nolan (1995) retomam a questão das relações entre a representação fonológica da assimilação e a natureza fonética da assimilação de ponto de articulação, examinando desta vez a seqüência [s $\left.\int\right]$. Essa seqüência consonantal foi examinada em expressões do tipo restock[s (\#) S]elves, inseridas em uma sentença, em que uma fronteira sintática pode estar presente. Três possibilidades de assimilação são consideradas: a) o articulador desliza de uma posição a outra, situação esta chamada de segmento de contorno; b) o articulador adota desde o início a segunda especificação; c) uma articulação intermediária entre as duas posições, conforme proposto por Browman \& Goldstein (1989). As possibilidades previstas pela Fonologia Articulatória são as seguintes, considerando-se a sobreposição progressiva dos gestos articulatórios:

A
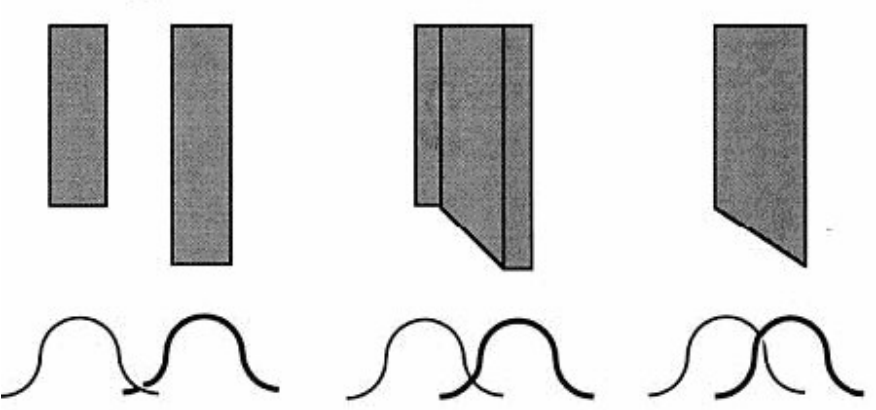

D
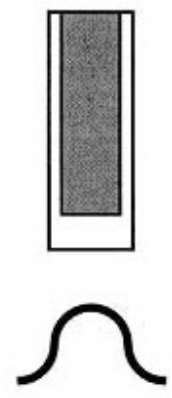

FIGURA 1 - Representação esquemática da acomodação crescente entre [s] e [ $]$, como padrões espectográficos (acima) e sobreposição de gestos (abaixo). (HOLST; NOLAN, 1995) 
Sem entrar na discussão sobre a melhor representação fonológica para a assimilação, o que nos interessa aqui é que os autores detalham essas possibilidades assimilatórias, ilustrando-as com documentos acústicos (espectrogramas e espectro de freqüências), que mostram uma progressão que parte de dois padrões estáveis e distintos, mais comuns no contexto de fronteira sintática, passando por um padrão em que se passa suavemente de um padrão de tipo [s] para um padrão de tipo [ $]$ ], chegando-se, finalmente, a um padrão espectral estável mais próximo do [S] do que do [s].

Nolan et al (1996) aprofundam a discussão dos princípios que governam os processos assimilatórios, que visam a explicar as relações entre um nível fonológico discreto e o contínuo fonético. Defendem a idéia de que certos processos assimilatórios são fonéticos, como pretende a Fonologia Articulatória, isto é, processos de apagamento, co-articulação, enfraquecimento, assimilação são o resultado da reação dinâmica dos articuladores às sucessivas especificações fonológicas. Mas, contrariamente a Browman \& Goldstein, sustentam que há certo tipo de assimilação que é fonológico, cognitivo.

Neste artigo, uma réplica às críticas de Browman \& Goldstein às conclusões de Holst and Nolan (1995), os autores detalham suas idéias a respeito do caráter fonético ou fonológico dos processos assimilatórios. Exploram a teoria quântica (STEVENS, 1972, 1989) na explicação dos fenômenos coarticulatórios, opondo um efeito quântico fraco a um efeito quântico forte. No efeito quântico fraco, o movimento gradual do articulador produz modificações contínuas do conduto vocal, tendo como conseqüência modificações acústicas contínuas, mas não lineares. Já no efeito quântico forte, as modificações graduais do movimento articulatório provocam mudanças acústicas abruptas. Perkell et $a l$, segundo os autores, atribuem esse efeito quântico forte aos processos coarticulatórios da seqüência [s $\left.\int\right]$. Nolan et al, entretanto, embora tenham desenvolvido idéias instigantes com relação à natureza dos processos coarticulatórios, reconhecem que os resultados de seus experimentos não foram suficientes para demonstrá-las.

Também interessado na busca de princípios que regulam a produção da fala na coordenação dos movimentos articulatórios, Byrd (1996) examina, com o auxílio da eletropalatografia, sequiências de duas consoantes, levando em conta que a fronteira de palavra, (\#), pode ocorrer antes da seqüência consonantal, entre as consoantes da sequiência consonantal e após a seqüência consonantal: 
H1: Consoantes têm menor número de contatos língua-palato na posição de coda do que na posição de ataque.

H2: O contato língua-palato é mais variável (magnitude e duração) em posição de coda do que em posição de ataque.

Seus experimentos levam em conta, sobretudo, sequiências de consoantes oclusivas alveolar-velar e velar-alveolar, havendo, entretanto, em alguns casos, a presença da fricativa alveolar.( Exemplos: Type bad gab again,Type bag dab again,Type bass gab again). Seus resultados confirmam suas hipóteses:

We have found evidence that onset clusters, coda clusters, and heterosyllabic sequences dif fer in their inter-gestural timing and in reduction. However, the precise nature of these ef fects depends on the consonants in the sequence (BYRD, 1996, p.235).

Recasens \& Pallarès (2006) discutem os processos de co-produção no catalão. Segundo esses autores, a Fonologia Articulatória prevê que dois ou mais gestos contíguos fundem-se para formar uma constrição intermediária. Estudos têm indicado, entretanto, segundo os mesmos autores, a possibilidade de uma assimilação completa ou de um deslizamento de uma articulação para a outra. A seqüência [s $\int$ ] é dada como exemplo de assimilação regressiva, tanto no catalão como no inglês. Já a sequiência [ $\left.\int \mathrm{s}\right]$ no catalão favorece a fusão, ou seja, uma constrição intermediária entre esses dois gestos articulatórios.

\section{A eletropalatografia}

A eletropalatografia, EPG, é uma técnica que possibilita a obtenção de informações espaciais e temporais, a cada $5 \mathrm{~ms}$, em tempo real, dos contatos da língua com a abóbada palatina, mais precisamente, as regiões alveolar, pós-alveolar, palatal e, por vezes, velar. Consiste de um palato artificial (1,5mm de espessura), de tipo ortodôntico, recoberto com 62 eletrodos dispostos em linhas e colunas. Esses eletrodos estão ligados a um eletrodo externo, constituindo um circuito elétrico de baixa voltagem. Quando há o contato da língua com o palato, fecha-se o circuito, registrando-se, assim, com precisão, a região da abóbada palatina em que ocorreu o contato. Esses registros aparecem em imagens, as imagens eletropalatográficas ou imagens IEPG na tela de um computador, ao qual está conectado o palato artificial. 


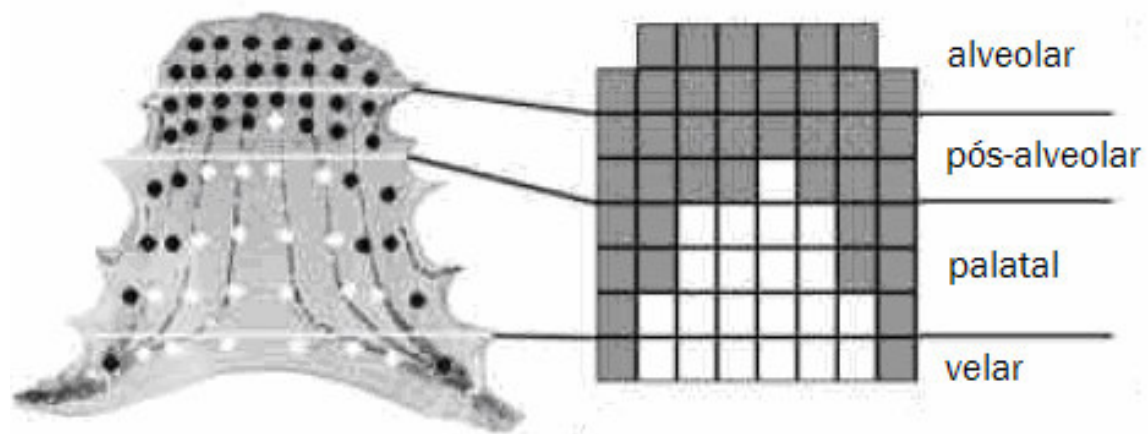

FIGURA 2 - Palato artificial apresentando 62 eletrodos, mostrando contato lingual na área escura (à esquerda). Do lado direito, a imagem EPG correspondente. (Adaptado de MEYNADIER, 2003, p. 87)

\section{Materiais e método}

Um locutor, sexo masculino, gravou o corpus (ANEXO 1), contendo palavras do português, variedade de Belo Horizonte, em que a fricativa alveolar [s] aparece em diferentes contextos:

1. início de sílaba, início de palavra: sala, salada;

2. início de sílaba, meio de palavra: cassada, massada;

3. final de sílaba, final de palavra: as, datas;

4. final de sílaba, meio de palavra: cascas, pastas;

5. [s] em final de sílaba/[s] início de palavra: as salas, as saias;

6. [s] em final de sílaba/[J] em início de palavra: as chagas, as chaves.

Já a fricativa pós-alveolar [ $]$ ] aparece em dois contextos:

1. início de sílaba, início de palavra: chagas, chave;

2. início de sílaba, meio de palavra: rachada, cachaça.

As palavras são dissílabas e trissílabas, paroxítonas, inseridas em duas frases veiculares: "fala pra ela" ou "eu disse cinco vezes.

Depois de sessões de treinamento e de ajustes do palato artificial, que permite o registro dos contatos língua-palato, foi feita a gravação do corpus no equipamento Physiologia, equipado de um EPG "Reading", no Laboratório "Parole et Langage" do Centro Nacional de Pesquisa Científica de Aix-en-Provence, França. 
Para a exploração dos dados eletropalatográficos, foi instalado, no Laboratório de Fonética da Faculdade de Letras da UFMG, o programa MES (Motif editor for speech signals), desenvolvido pelo engenheiro Robert Espesser, que sincroniza sinal acústico, espectrograma e imagem eletropalatográfica.

Podemos dizer que a imagem eletropalatográfica pode apresentar um dos três estados seguintes: a) em primeiro lugar, todos os eletrodos podem estar ativados, como na figura $3 .^{2}$

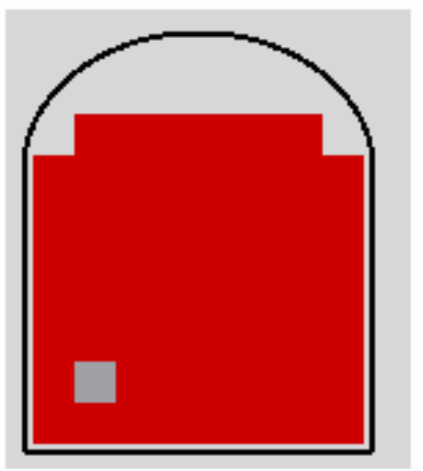

FIGURA 3 - Todos os contatos ativados, com exceção do contato $\mathrm{P} 3 \mathrm{C} 2$, inoperante

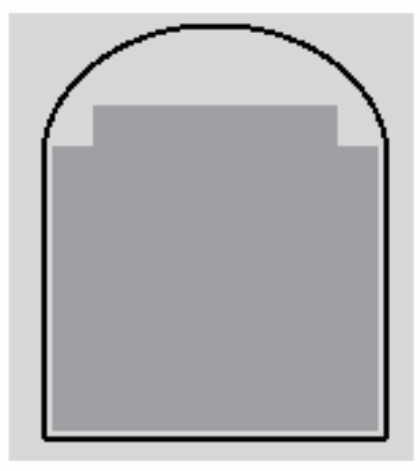

FIGURA 4 - Imagem EPG do [a] tônico de salada, mostrando a ausência de contato lingual.

Isso acontece antes do início de uma gravação, no momento em que a língua pode tocar toda a área recoberta por eletrodos, quando diferentes movimentos com a língua são possíveis; b) inversamente, a figura 4 mostra uma imagem palatográfica em que nenhum dos eletrodos é ativado, o que acontece em vogais abertas; c) finalmente, a imagem palatográfica exibe diferentes configurações dos contatos da língua na região palatina no momento em que se fala, como veremos neste estudo.

Para a exploração das imagens fornecidas pela eletropalatografia, utilizaremos em parte a metodologia desenvolvida por Meynadier (2003) e, em parte, o que foi apresentado por Reis \& Antunes (2002). Assim, para identificar os diferentes pontos de articulação, vamos nos basear nos esquemas das figuras $5,6,7$ e 8 . 


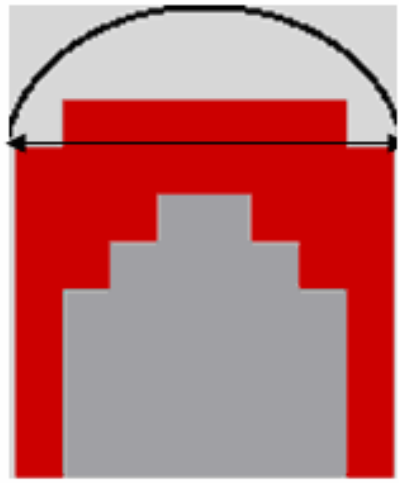

FIGURA 5 - Eixo transversal, indicando o ponto de articulação alveolar.

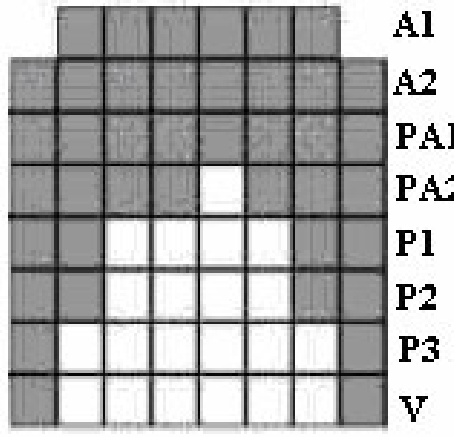

FIGURA 7 - Pontos de articulação: A : alveolar; PA: pós-alveolar; P: palatal; V: velar. (Adaptado de MEYNADIER, 2003, p. 87)

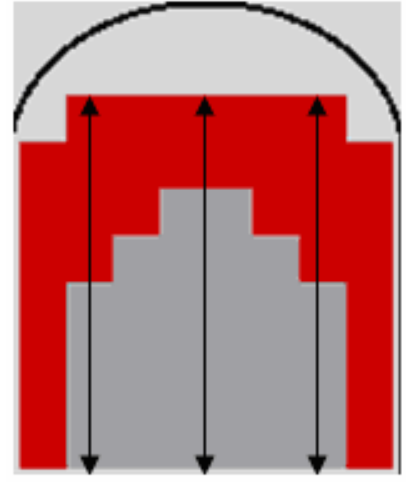

FIGURA 6 - Eixos longitudinais: central, C e laterais, $\mathrm{L}$.

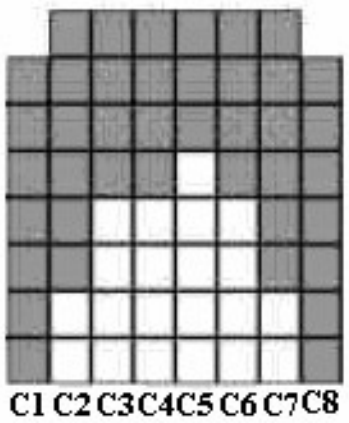

FIGURA 8 - Colunas de 1 a 8 da imagem EPG. (Adaptado de MEYNADIER, 2003, p. 87)

Para a exploração das imagens EPG, vamos considerar dois eixos: um eixo transversal e um eixo longitudinal. O eixo transversal é representado por um segmento de reta que passa pelo centro de uma zona de articulação, no sentido horizontal, de uma extremidade a outra da imagem EPG.

O eixo longitudinal, que acompanha a linha do septo lingual, subdivide-se em três eixos: eixo longitudinal central, eixo longitudinal lateral esquerdo e eixo longitudinal lateral direito. O eixo longitudinal central passa pelas colunas $\mathrm{C} 45$, enquanto cada eixo longitudinal lateral inclui até três colunas de eletrodos, L123, à esquerda e L678 à direita. Cagliari (1974, p. 40) sugere que linhas longitudinais 
que não sejam a linha média seriam supérfluas. Dentro de uma perspectiva lingüística, esse autor tem razão, pois a importância particular do eixo longitudinal central está no fato de que, na sua interseção com o eixo transversal, define-se o alvo fonológico. Entendemos, entretanto, que a descrição fonética deve ultrapassar o interesse estritamente fonológico, fornecendo também informações para o estudo patológico, para o ensino de línguas, para a identificação do locutor, enfim, para os diferentes especialistas interessados na fala. Uma descrição fonética não pode ignorar que uma oclusiva alveolar, para ser oclusiva, não pode restringir o contato lingual à zona alveolar. Quando classificamos um fone como oclusivo alveolar, trata-se, pois, de uma simplificação (ABERCROMBIE, 1967), porque atende aos interesses da análise fonológica, ou de uma certa análise fonológica.

O detalhamento do contato lingual se faz a partir do ponto em que os eixos transversal e longitudinal se cruzam. Para isso, utilizaremos as seguintes referências, para cada eixo: para cada contato lingual, identificaremos a zona de articulação, as linhas de contato para cada zona de articulação, assim como as colunas. Serão, em alguns casos, contados os eletrodos ativados ou não ativados nas linhas e nas colunas. Vamos nos referir às linhas dos pontos de articulação como A1 (ponto alveolar, linha oㅡㄴ), A2 (ponto alveolar, linha nº 2), PA1 (ponto pós-alveolar, linha no 1), PA2 (ponto pós-alveolar, linha no 2 ), P1 (ponto palatal,

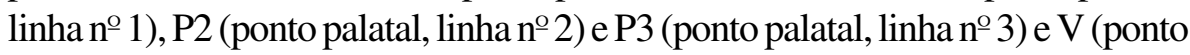
velar), que corresponde à última fileira de eletrodos. Neste caso há apenas uma indicação do contato velar, que ocorre fora do alcance do palato artificial. Quando o contato implicar mais de uma linha, indicaremos a identificação da zona de articulação e, em seguida, os algarismos referentes a cada linha dessa zona de articulação: A1, A2 ou A12; PA1, PA2 ou PA12 e P1, P2, P3, P12, P23 ou P123.

Neste estudo, utilizamos o sinal acústico de fala, o espectrograma, o baricentro e a imagem EPG. Todos esses traçados sincronizados, de forma que, para obter as diferentes configurações dos contatos língua-palato durante a produção do fone fricativo, basta deslocar o cursor sobre o sinal sonoro para que a imagem EPG indique os contatos que ocorrem naquele momento da produção do fone, obtendo-se, ao mesmo tempo, a análise espectrográfica e curva do baricentro. Para se estabelecer uma referência exata para as imagens EPG, mediu-se a duração do fone, em milissegundos (ms), indicando-se, a partir daí, o tempo do sinal sonoro correspondente à imagem EPG. A configuração 
eletropalatográfica mais estável será indicada pela palavra max (número máximo de contatos), que coincide com o maior número de contatos no ponto de articulação do fone em questão.

Vamos basear nosso estudo num índice de não alveolaridade, resultado de um cálculo do centro de gravidade dos contatos EPG em todo o palato. Para isso, vamos utilizar um instrumento de análise, o baricentro, que faz automaticamente o cálculo, instrumento esse disponível no programa de análise da fala MES. Nessa análise, o índice varia de +2 , acima de uma linha zero, a -2 , abaixo da linha zero. Os fones com maior contato na região palatal e velar terão um índice alto, como acontece com as vogais e oclusivas velares. Os fones com maior contato na região alveolar terão um índice baixo. De acordo com as nossas análises, os fones fricativos alveolares terão um índice negativo no baricentro, enquanto os fones fricativos pós-alveolares terão um índice positivo.

Para descrever os processos de co-articulação das seqüências de fricativas, vamos, primeiramente, fazer uma descrição dessas fricativas nas várias posições em que se encontram na sílaba e na palavra. Com base nas informações eletropalatográficas e acústicas assim obtidas, vamos, então, examinar as sequiências consonantais.

\section{Resultados e discussão}

\subsection{Fricativas alveolar e pós-alveolar não vozeada}

Os fones fricativos alveolares caracterizam-se por uma ausência de contato no eixo longitudinal central, com maior número de contatos, no eixo transversal, numa zona que pode ir de A1 a PA1. Na figura 9 (lado esquerdo), que apresenta parte dos traçados acústicos da palavra "sala", o baricentro indica um nível de não alveolaridade muito baixo para o fone [1], que chega ao seu nível mínimo (-2), e um nível de não alveolaridade menor para o [s], (-0,76). Aimagem EPG indica uma articulação da fricativa alveolar que pode ser considerada canônica, com um contato mais importante, no eixo transversal, nas regiões A2 e PA1, com uma abertura no eixo longitudinal na coluna C5.

As pós-alveolares caracterizam-se, na sua configuração articulatória mais freqüente, no eixo transversal, por um maior número de contatos em PA12, com uma abertura no eixo longitudinal nas colunas $\mathrm{C} 45$. Conforme se pode observar 

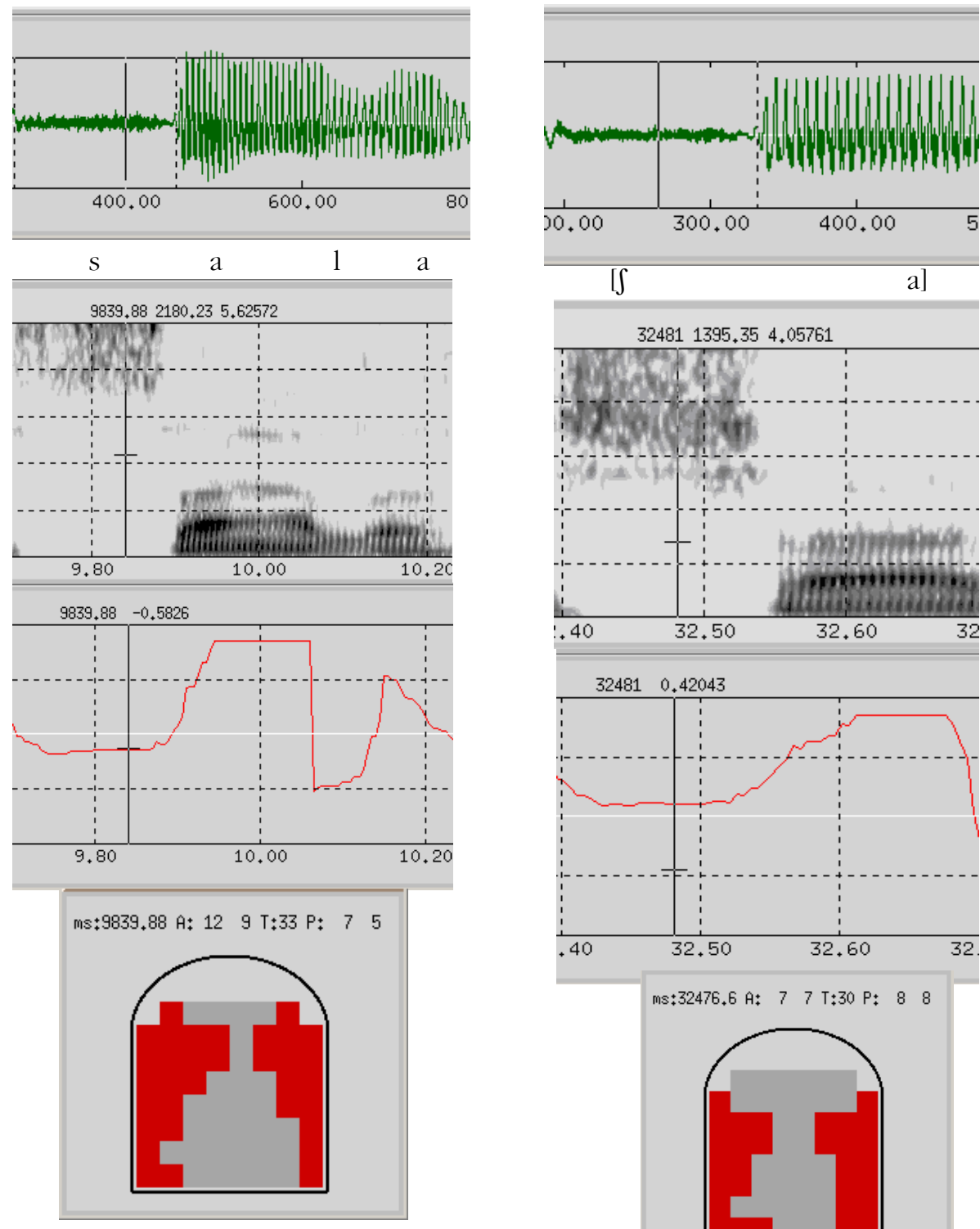

[s] da palavra "sala"

Duração: $184 \mathrm{~ms}$ - max $125 \mathrm{~ms}$

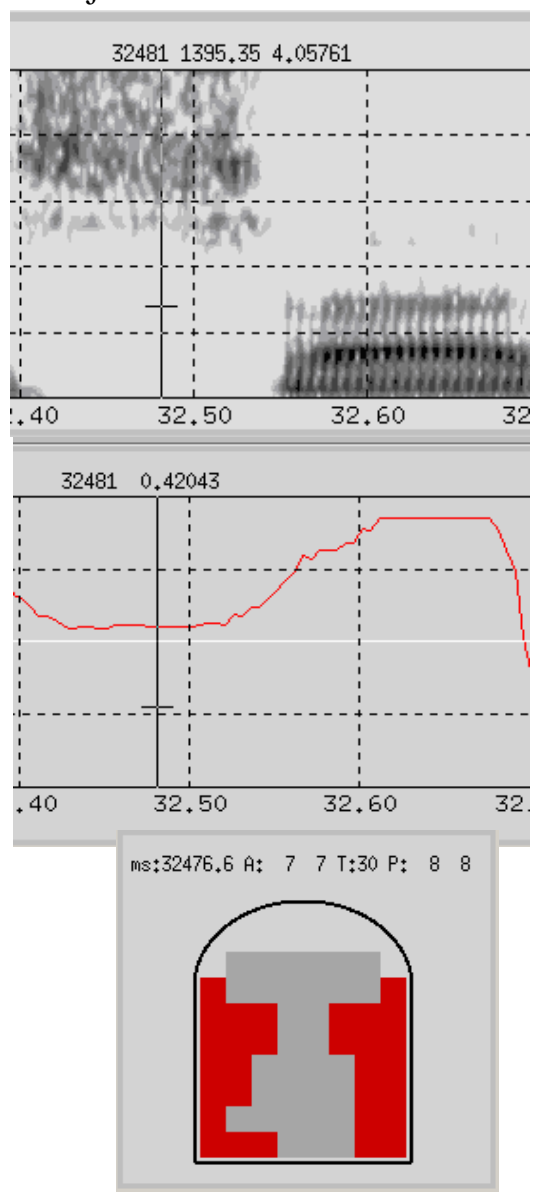

[Sa] de fachada

Duração: 144ms - max 71ms CRRM01c

FIGURA 9 - Sinal de fala, espectograma, baricentro e imagem EPG do fone [s] na palavra"sala" e do fone [S] na palavra "fachada" (corpus). (CRRM01c) 
na figura 9 (lado direito), a curva do baricentro está acima da linha zero, indicando alto índice de não alveolaridade. As pós-alveolares podem também apresentar maior número de contatos, no eixo transversal, apenas em PA1 ou mesmo em PA12P1. Neste último caso, com quatro colunas de abertura no eixo longitudinal, o que resulta numa fricativa muito fraca, como se pode observar no espectrograma. No traçado da direita, em "fachada", há um maior número de contatos, no eixo transversal, em PA12. No eixo longitudinal central, são duas colunas para a abertura, $\mathrm{C} 45$.

Já a fricativa alveolar (ANEXO 2) caracteriza-se na sua configuração articulatória mais freqüente, no eixo transversal, por um maior número de contatos em A2. A abertura no eixo longitudinal central varia entre duas colunas, C45, e três colunas, C456. Essa variabilidade que se observa no eixo longitudinal central pode se ver também no eixo transversal, ocorrendo contatos também em A1 e em PA1. Os contatos observados na fricativa alveolar foram A12, A2, A2PA1 e até mesmo A12PA1. Essa variabilidade de contatos é devida a vários fatores, como o contexto fonético e a força articulatória. A força articulatória está associada ao número de contatos. Quanto maior o número de contatos, maior força articulatória é investida na produção do fone. A duração pode ser um outro fator associado à maior força articulatória. Quanto mais longo o fone, também maior é a sua força articulatória. Assim, as fricativas em posição de ataque, em posição tônica, apresentam uma duração que é aproximadamente o dobro da duração das fricativas em posição de coda, no corpus examinado.

Examinando-se os contatos do fone fricativo [s] na região alveolar, há duas características básicas: a) ponto bem definido, com abertura longitudinal central estreita, $\mathrm{C} 45 \mathrm{e} \mathrm{b}$ ) ponto não muito bem definido com abertura longitudinal larga, C456. A zona de articulação da vogal parece ter um efeito sobre os contatos alveolares, pois, nas palavras "silo" e "sela", o estreitamento maior ocorre em A12. Já na maioria das palavras em que a vogal é baixa, como em "sala", "sacada", "sacana", "salada", o ponto de maior estreitamento ocorre a partir de A2. Imagens EPG mostram que, nesse caso, o ponto de articulação é A2PA1, ou seja, uma articulação recuada de uma linha com relação ao contexto de vogal palatal (ANEXO 3). 


\subsection{A co-produção articulatória na seqüências /s \# s/ /s \# s/}

No português, a fricativa alveolar encontra-se, em alta frequiência, tanto em posição de ataque como em posição de coda, no início, meio e fim da palavra. Vamos examinar esse fone, com o auxílio da eletropalatografia e, também, de traçados acústicos, nos diversos contextos em que se encontra em nosso corpus, interessando-nos, em particular, pelo processo de co-produção, quando ocorrem as seqüências /s \# s/ /s \# $\int /$.

A primeira sequiência é muito freqüente, uma vez que a fricativa alveolar é marca de plural no sintagma nominal. No dialeto em questão, a seqüência/s \# s/ é articulada no ponto de articulação alveolar. Observa-se na produção da fricativa o que normalmente se vê na produção de qualquer fone dentro de uma sílaba: processos de co-articulação com o fone que precede e com o que se segue.A questão que se coloca é se, na conversa normal, a seqüência é articulada como dois fones distintos ou um único fone, resultado de assimilação completa. Já a seqüência /s \# $\int /$ apresenta natureza fonética variável, o que justifica um estudo fonético mais detalhado. Em alguns dialetos do PB, como há palatalização da fricativa alveolar em posição de coda, os processos de coprodução são de natureza diversa, o que não vai ser examinado neste trabalho.

\subsubsection{A seqüência /s \# s/}

Nos casos examinados, ocorre a seqüência [s \# s], como vimos anteriormente, quando o artigo definido, no plural, precede uma palavra iniciada com [s], como em "as salas", "as saias", "as sapas", "os cestos", "os socos". Vamos descrever, primeiramente, o [s] em posição de coda, em seguida o [s] em posição de ataque, para depois examinarmos a seqüência /s \# s/. Mostramos, inicialmente, como são distintos os processos co-articulalatórios na vogal aberta e na vogal fechada (artigo feminino e masculino). Descrevemos, em seguida, o [s] em posição de coda em [es'pastes] e o [s] em posição de ataque em ['sale] $\mathrm{e}$, por fim, a seqüência /s \# s/ em /assaias/. Documentos eletropalatográficos e acústicos correspondentes são apresentados nos anexos.

No nosso corpus, a fricativa, correspondente à marca de plural, se encontra no artigo feminino, [es] e masculino, [us]. No caso da vogal mais fechada, observa-se uma co-articulação mais precoce com a fricativa do que no caso da vogal baixa. Como se pode ver na figura 10, numa vogal que tem uma 


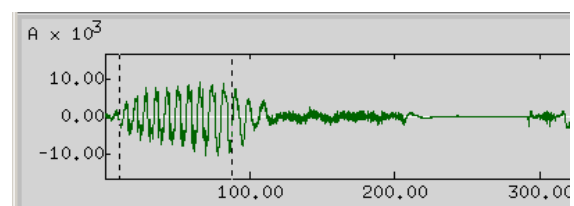

XRSCM0006 SONA SPECIAL (bande 250.00 (Hz) f8p
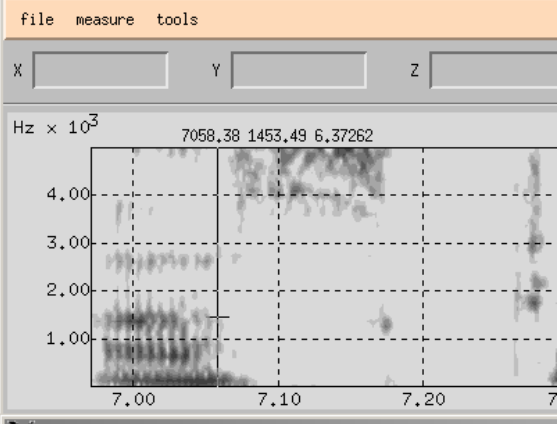

X RSCM0006 barycentre palais comple
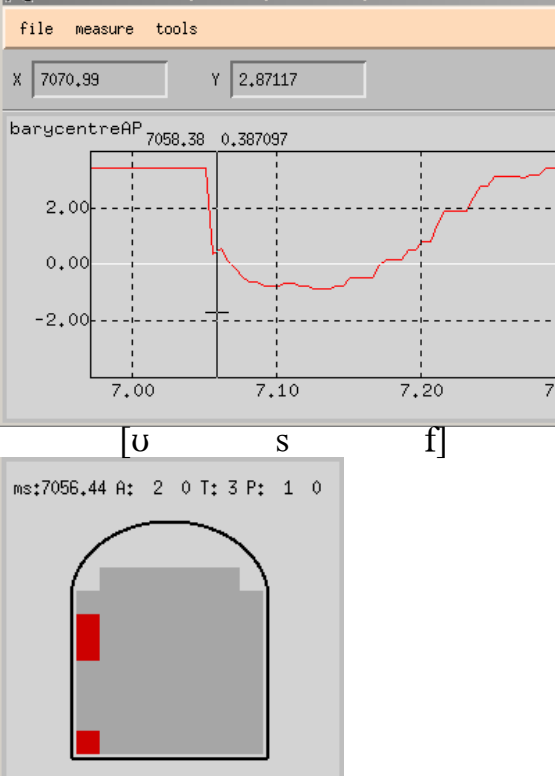

Co-articulação da vogal[ø] com a fricativa[s] que se segue em [rs'fahpes] Duração do [e] 102ms; $\mathrm{t}: 78 \mathrm{~ms}$.
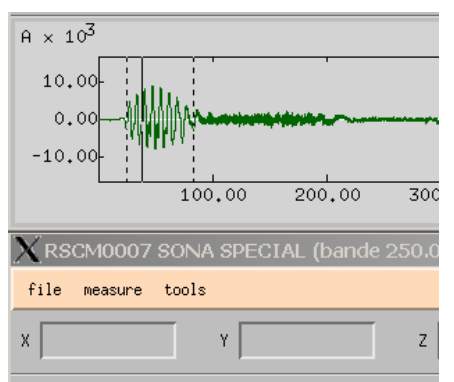

$\mathrm{Hz} \times 10^{3} 7475.812063 .953 .68233$
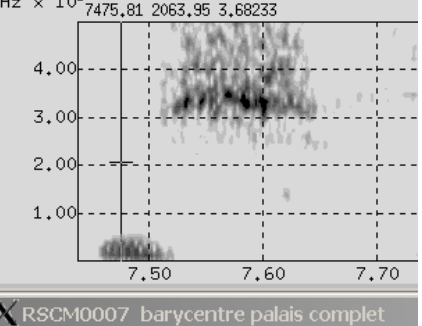

file measure tools
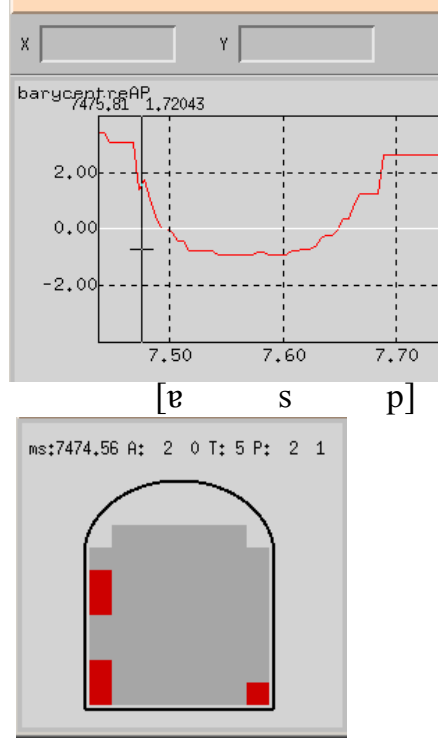

Co-articulação da vogal [u] com a fricativa [s] que se segue em [us'ferIIs]. Duração do [u]. $58 \mathrm{~ms} ; \mathrm{t}: 14 \mathrm{~ms}$.

FIGURA 10 - Co-articulação da vogal (artigo definido) com a consoante [s] da palavra que se segue, formando a sequiência [es][Us] ( $\mathrm{t}$ = indica o tempo na vogal em que os primeiros contatos da fricativa se iniciam). 
duração de 58ms, a co-articulação com a consoante fricativa que se segue se inicia aos $23 \mathrm{~ms}$ da vogal, que apresenta um índice no baricentro muito baixo para vogal $(+1,05)$. Já na vogal baixa, a co-articulação se inicia aos $78 \mathrm{~ms}$ de uma vogal que tem uma duração de $96 \mathrm{~ms}$. O índice do baricentro ultrapassa +2 no meio da vogal para cair a +0.38 aos $78 \mathrm{~ms}$.

Da mesma forma, com relação ao fone que se segue, a fricativa alveolar pode perder contatos, no final da sua realização, na região alveolar, ganhando, ao mesmo tempo, contatos na região palatal e velar, se o fone que se segue é consonantal velar ou uma vogal. Contrariamente, quando o fone que se segue é uma consoante alveolar, ganha contatos na região alveolar ou, pelo menos, não perde contatos.

Como se pode observar em [espas] de "as pastas" (ANEXO 4), já na primeira vogal, que tem uma duração de $93 \mathrm{~ms}$, inicia-se, aos $80 \mathrm{~ms}$, o processo de co-articulação com a consoante fricativa alveolar que se segue. Esta, que também tem a duração de $93 \mathrm{~ms}$, apresenta a maior constrição no nível de A2, com um estreitamento máximo por volta de $54 \mathrm{~ms}$. A constrição máxima dura $19 \mathrm{~ms}$. Até os $54 \mathrm{~ms}$ da consoante labial que se segue ainda há resquícios da articulação da fricativa alveolar. Aos $107 \mathrm{~ms}$ da realização do [p], não há mais sinais da fricativa, que apresenta já uma articulação típica da vogal [a] que se segue. A abertura, no eixo longitudinal central, é de duas colunas, C45, da constrição máxima até o final (40ms) da fricativa.

$\mathrm{Na}$ fricativa em posição de ataque da palavra sala em "fala sala" (ANEXO 5), o [s], com uma duração de 190ms, inicia o movimento em direção aos alvéolos aos $45 \mathrm{~ms}$ da vogal [e] que precede. Aos $42 \mathrm{~ms}$, uma constrição alveolar se define mais nitidamente no nível da linha A2, recebendo, aos 55ms contato na linha PA1. Nas imagens seguintes, observa-se, primeiro, uma articulação A12P1, que passa, em seguida, aos $160 \mathrm{~ms}$, a A2PA1. Considerando a constrição máxima, que dura $62 \mathrm{~ms}$, e os contatos que mais tempo permanecem ao longo da produção da consoante, pode-se afirmar que o ponto de articulação é A2PA1. A co-articulação com a vogal [a] que se segue inicia-se aos $153 \mathrm{~ms}$ da fricativa. As últimas informações dessa articulação alveolar aparecem aos $11 \mathrm{~ms}$ da vogal [a] que se segue. Até os $66 \mathrm{~ms}$ da fricativa, a abertura, no eixo longitudinal central, é de três colunas, C45L6. Da constrição máxima, aos 90ms até os $152 \mathrm{~ms}$ é de duas colunas, $\mathrm{C} 45$.

Comparando-se a fricativa nas duas posições silábicas, a fricativa em posição de ataque tem uma constrição máxima com abertura $C 45$ durante $62 \mathrm{~ms}$, 
enquanto, na fricativa em posição de coda, essa duração cai para 40ms. Além disso, aquela apresenta 56ms de abertura com três colunas C45L6, enquanto nesta a abertura é reduzida a $20 \mathrm{~ms}$.

Resumindo: a fricativa em posição de coda, correspondente à marca de plural no artigo definido, e a fricativa em posição de ataque, na sílaba inicial de substantivos, como sala, salada, apresenta, no eixo transversal, um maior número de contatos nas linhas A12PA1, com predominância para A2 na constrição máxima, e um eixo longitudinal central de duas colunas C45 (ANEXO 6).

Na seqüência /s \# s/ do sintagma "as saias" (ANEXO 7), os primeiros contatos se iniciam aos $72 \mathrm{~ms}$ da vogal [e]. Aos $25 \mathrm{~ms}$, inicia-se uma constrição no nível A2PA1, com três colunas de abertura no eixo longitudinal central, C45L6 até os 56ms, quando se acrescenta mais um contato em A1. De $92 \mathrm{~ms}$ a $142 \mathrm{~ms}$ ocorre a constrição máxima em A2, com uma abertura longitudinal central de duas colunas, C45. A partir de então, vão se perdendo os contatos alveolares num processo de co-articulação com a vogal [a] que se segue. Em /as'salas/, a produção da fricativa segue o mesmo padrão. Já em /as'sapas/ a constrição máxima se situa em A2PA1, com três colunas no eixo longitudinal central, C45L6.

Comparando-se a fricativa alveolar na posição de ataque e de coda com a sequiência consonantal, não nos parece haver elementos que indiquem diferença significativa entre a produção da seqüência de consoantes fricativas alveolares e a produção de uma única fricativa em posição de ataque. Não pudemos identificar pistas eletropalatográficas ou acústicas que indicassem a produção de duas fricativas distintas. Até a duração da seqüência de fricativas não é significativamente distinta da consoante em posição de ataque. As informações fornecidas pelo baricentro (-0,68 para a posição de coda, -0.97 em posição de ataque e de -0,81 para a seqüência consonantal) são compatíveis com o índice de não alveolaridade da fricativa alveolar.

No Anexo 10, apresentamos o espectro de freqüências da fricativa alveolar de "as salas", no início, meio e fim da consoante, indicando-se um pico de freqüência acima de $5 \mathrm{KHz}$. Da mesma forma, o espectrograma e os espectros de [S] de "fachada" podem ser comparados com o espectro da seqüência $\left[\mathrm{s} \int\right]$. 


\subsubsection{A seqüência /s \# $\int /$}

Examinada a articulação da fricativa alveolar através da eletropalatografia e, na análise acústica, o espectrograma e seu espectro de freqüência, vamos agora realizar o mesmo procedimento com relação à fricativa pós-alveolar. Vamos descrever a produção dessa fricativa na posição de ataque na palavra "fachada" e, posteriormente, na seqüência consonantal "as chaves".

Na palavra fachada (ANEXO 8) inicia-se o processo de co-articulação aos $79 \mathrm{~ms}$ na vogal átona da palavra "fala", [e] (86ms). A sequiência de fricativas dura $181 \mathrm{~ms}$. Apenas aos 55ms se define uma articulação pós-alveolar em PA1 com uma abertura longitudinal central de duas colunas, $\mathrm{C} 45$, onde atinge a constrição máxima até $106 \mathrm{~ms}$, quando então se inicia a co-articulação para a vogal [a]. Aos $23 \mathrm{~ms}$ da vogal [a], registram-se as últimas pistas da articulação fricativa.

Na sequiência [s J] de /as' Javis/ (ANEXO 9), inicia-se o processo de coarticulação da vogal que precede a fricativa com a fricativa aos $57 \mathrm{~ms}$ na vogal que tem uma duração de $81 \mathrm{~ms}$. Aos $28 \mathrm{~ms}$ inicia-se uma maior constrição no nível de PA1 que vai permanecer até os $118 \mathrm{~ms}$. A partir daí, a constrição ocorre em PA12, típica da fricativa pós-alveolar, indo até $154 \mathrm{~ms}$, quando começa a coarticulação com a vogal [a] que se segue.

Em relação à sequiência /s \# s/, o que se observa em /s \# S/ é que, em nenhum momento, a constrição não atinge a linha $\mathrm{A} 2$, típica da articulação alveolar. Dos 44ms aos 118ms, quando ocorre a constrição máxima, há maior número de contatos em PA1 com uma abertura longitudinal central de duas colunas. A curva do baricentro indica, assim, um baixo índice de não alveolaridade até os 98ms. (-0,094) Só aí então é que o índice de não alveolaridade se torna levemente positivo (0.029). Pode-se observar, então, que há pelo menos um contato em A1 $\mathrm{em} / \mathrm{s} \# \int /$, o que não ocorre em $/ \int /$, podendo ocorrer até cinco contatos em A2, quando em $/ \int$ / só aparecem dois contatos. Isso aponta para uma articulação híbrida no início da seqüência /s $\int$ / que não corresponde a /s/ nem a $/ \int /$.

De fato, examinando-se o espectrograma (ANEXO 9), vê-se uma inclinação nítida na base do ruído, na sua base, entre 4KHz a 2,6 KHz. Gráficos do espectro de freqüência obtidos em três momentos da sequiência /s \# S/, início, meio e fim, comprovam que os dois primeiros picos de frequiência situam-se em torno do patamar de $4 \mathrm{KHz}$, enquanto o último situa-se bem abaixo de $4 \mathrm{KHz}$, ambos distintos do pico de freqüência do [s], que se situa acima de $5 \mathrm{KHz}$. 
Podemos, pois, concluir que os documentos EPG e acústicos apontam para uma realização da sequiência $/ \mathrm{s}$ \# $/$ / que se aproxima do $/ \delta /$, mas com um certo índice negativo de não alveolaridade, $-0,22$, no seu início até os $100 \mathrm{~ms}$, chegando a 0,19 aos 139ms. confirmando a previsão da Fonologia Articulatória de uma articulação intermediária entre os dois fones da seqüência consonantal.

\section{Conclusão}

A eletropalatografia, técnica que fornece imagens EPG sobre os contatos língua-palato, tem se constituído num instrumento precioso no registro de fenômenos de co-articulação e co-produção das seqüências de fones da fala. Neste estudo, mostrou-se que a seqüência /s \# s/, presente neste corpus, não se distingue do /s/ em posição de ataque da sílaba Por outro lado, a sequiência /s \# S/ parece resultar em um fone intermediário entre o/s/ e o/J/, de acordo com um efeito quântico fraco e segundo as previsões da Fonologia Articulatória.

Este trabalho foi possível graças ao apoio do Laboratoire Parole et Langage do CNRS. Os pesquisadores Bernard Teston, Alain Ghio, Yohann Meynadier ajudaram na confecção e registro dos dados, e o pesquisador Robert Espesser instalou MES no Laboratório de Fonética da FALE/ UFMG e formatou o corpus para ser explorado por esse programa. Agradecemos, também, à Profa. Elizabeth Rodrigues Alfenas, da Faculdade de Oftalmologia da UFMG, que colaborou no melhor ajustamento do palato artificial.

\section{Notas}

${ }^{1}$ Vamos utilizar a expressão língua-palato para nos referir aos contatos da língua com os alvéolos e o palato duro.

${ }^{2} \mathrm{O}$ eletrodo $\mathrm{P} 3 \mathrm{C} 2$, por uma razão desconhecida, apresenta-se sempre desativado. 


\section{Referências Bibliográficas}

ABERCROMBIE, D. Elements of general phonetics. Chicago: Aldine, 1967.

BROWMAN, C. P.; GOLDSTEIN, L. Articulatory gestures as phonological units. Phonology, v. 6, p. 201-251, 1989.

BYRD, D. Influences on articulatory timing in consonant sequences. Journal of Phonetics, v. 24, p. 209-244, 1996.

CAGLIARI, L. C. A palatalização em português: uma investigação palatográfica. 1974. (Mestrado em Lingüística) - Instituto de Estudos da Linguagem. Universidade Estadual de Campinas, Campinas.

ESPESSER, R. MES: un environnement de traitement du signal. Actes des XXIèmes Journées d'études sur la parole, 10-14 juin 1996, Avignon, p. 447.

GIBBON, F.; NICOLAIDIS, K. Palatography. In: HARDCASTLE, W. J.; HEWLETT, N. (Ed.). Coarticulation in Speech Production: Theory, Data and Techniques. Cambridge: Cambridge University Press, 1999. p. 229-245.

HARDCASTLE, W. J. Physiology of speech production: an introduction for speech scientists. London: Academic Press, 1976.

HOLST, T. NOLAN, F. The influence of syntactic structure on [s] to [S] assimilation. In: CONNEL, B.; ARVANITI, A. (Ed.). Phonology and phonetic evidence: papers in laboratory phonology. Cambridge: Cambridge University Press, 1995. V. IV, p. 315-333.

NOLAN, F. The descriptive role of segments: evidence from assimilation. In: DOCHERTY, G. J.; LADD, D. R. (Ed.). Papers in laboratory phonology II. Cambridge: Cambridge University Press, 1992. p. 261-280.

NOLAN, F.; HOLST, T.; KÜHNERT, B. Modelling [s] to [S].accommodation in English. Journal of Phonetics, v. 24, p. 113-137, 1996.

MARCHAL, A. La Palatographie. Paris. Éditions du CNRS, 1988.

MEYNADIER, Y. Interaction entre prosodie et (co)articulation linguopalatale en français. 2003. 203 p. Thèse (Doctorat) - Université Aix-Marseille I.

PERKELL, J. S. et al. Articulatory and acoustic correlates of the [s $2 \mathrm{~s}$ ä] distinction. In: WOLF, J. J.; KLATT, D. H. (Ed.). Speech communication papers presented at the 97th meeting of the ASA, Cambridge MA 12-16 June, 1979. New York: Accoustical Society of America, 1979.

RECASENS, D; PALLARÈS, M.D. Coarticulation, assimilation and blending in Catalan consonant clusters. Journal of Phonetics, v. 20, p. 273-301, 2006. 
REIS, C.; ANTUNES, L.B. Estudo palatográfico de sons consonantais do português. In: REIS, C. (Org.). Estudos em fonética e fonologia do português. Belo Horizonte: FALE/UFMG, 2002. (Série Estudos Lingüísticos)

REIS, C.; ESPESSER, R. Estudo eletropalatográfico de fones consonantais e vocálicos do português brasileiro. Estudos da Língua(gem),v. 3, p. 181-204, 2006. (Questões de Fonética e Fonologia: uma Homenagem a Luiz Carlos Cagliari) Vitória da Conquista: Universidade Estadual do Sudoeste da Bahia.

STEVENS, K. N. On the quantal nature of speech: evidence from articulatoryacoustic data. In: DAVID, E. E.; DENES, P. B. (Ed.). Human communication: a unified y iew. New York: McGraw-Hill, 1972. p. 51-66.

STEVENS, K. N. On the quantal nature of speech. Journal of Phonetics, v. 17, p. 3-45, 1998. 


\section{ANEXOS}

Anexo 1

\section{Corpus}

1. cassada

(meio de palavra, posição tônica)

2. massada (meio de palavra, posição tônica)

3. passava (meio de palavra, posição tônica )

1. sacada

2. sacana

3. sarada

4. sanada

(início de palavra, posição átona)

(início de palavra, posição átona)

(início de palavra, posição átona)

1. fachada (início de palavra, posição átona)

2. rachada

(meio de palavra, posição tônica)

3. . rachada

4. sola

5. sela

6. silo

7. selo

8. suco (meio de palavra, posição tônica) (início de palavra, posição tônica) (início de palavra, posição tônica) (início de palavra, posição tônica) (início de palavra, posição tônica) (início de palavra, posição tônica)

1. as pastas (final de sílaba, final de palavra)

2. as datas (final de sílaba, final de palavra)

3. as dadas (final de sílaba, final de palavra)

4. as gatas (final de sílaba, final de palavra)

5. as classes (final de sílaba, final de palavra)

6. os pentes (final de sílaba, final de palavra)

7. as farpas (final de sílaba, final de palavra)

8. as cascas (final de sílaba, final de palavra)

1. as saias (s\#s)

2. as salas (s\#s)

3. as sapas (s\#s)

4. as suas (s\#s)

5. os socos (s\#s)

1. as chagas (s\# $)$

2. as chaves (final de palavra s\#f) 


\section{Anexo 2}

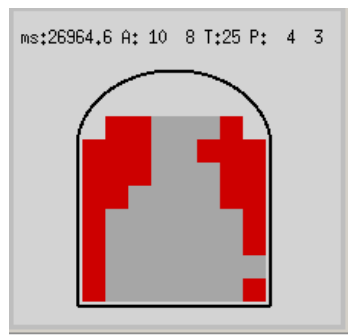

falaSala - $125 \mathrm{~ms}$
duraçẫo [s] $184 \mathrm{~ms}$

ms:29226.8 A: $10 \quad 9$ T:28 P: $5 \quad 4$

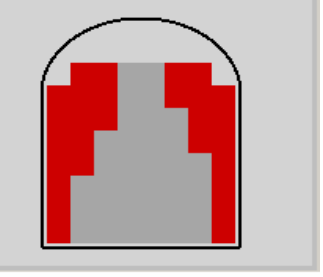

falaSela - max $50 \mathrm{~ms}$

duracẫo Is $1178 \mathrm{~ms}$

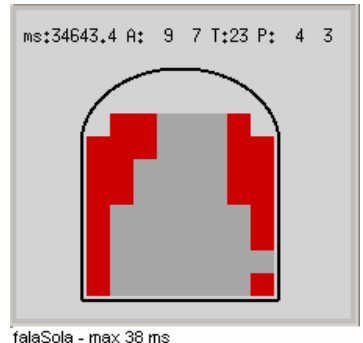

talaSola - max $38 \mathrm{~ms}$

duraçẫo [s] 183 ms
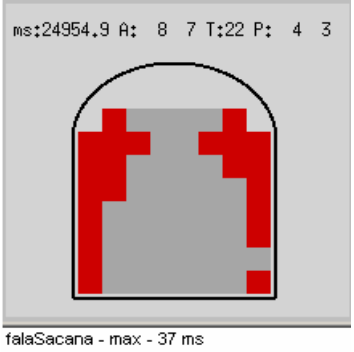

duraçấo do [s] $125 \mathrm{~ms}$

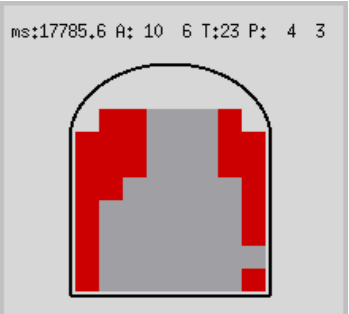

falasacada - $\max 73 \mathrm{~ms}$

Duração [s] : $132 \mathrm{~ms}$
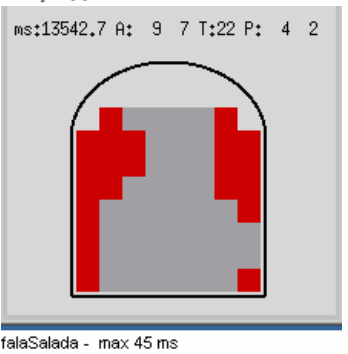

Duração [s] $151 \mathrm{~ms}$

ms:36673.8 A: $10 \quad 7 \mathrm{~T} \div 26$ P: $5 \quad 4$

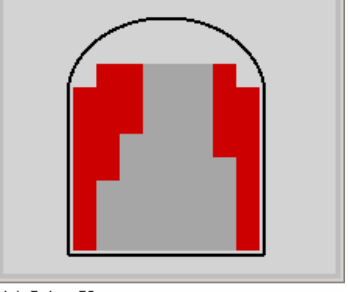

falaSelo - $58 \mathrm{~ms}$ - max

duraçăo [s] $197 \mathrm{~ms}$

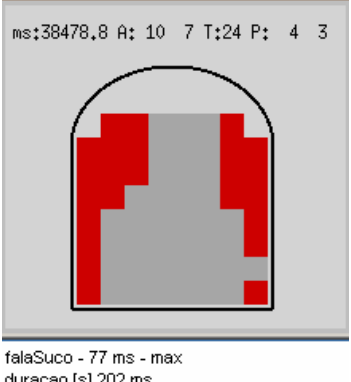

duraçao [s] $202 \mathrm{~ms}$

Imagens EPG do [s] em posição de ataque em sílabas acentuadas e não acentuadas, mostrando um momento da sua constrição máxima, indicando-se, também, a duração total do [s]. 


\section{Anexo 3}

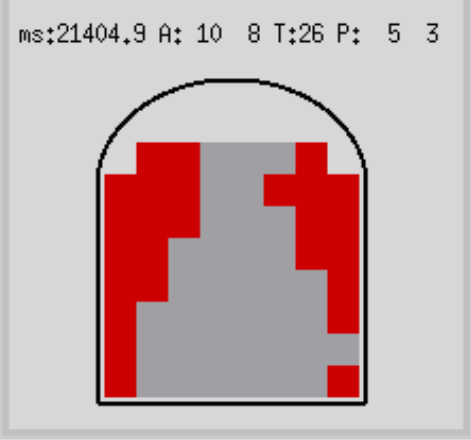

\section{caSSada}

Duração do [s] : 159ms

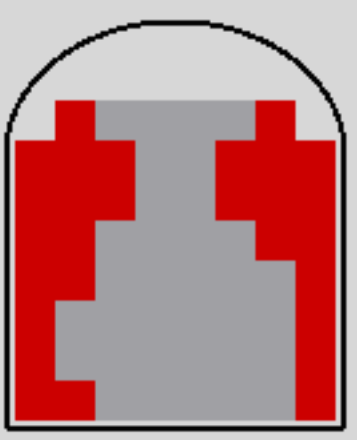

caSSada

Duração do [s] : 148ms
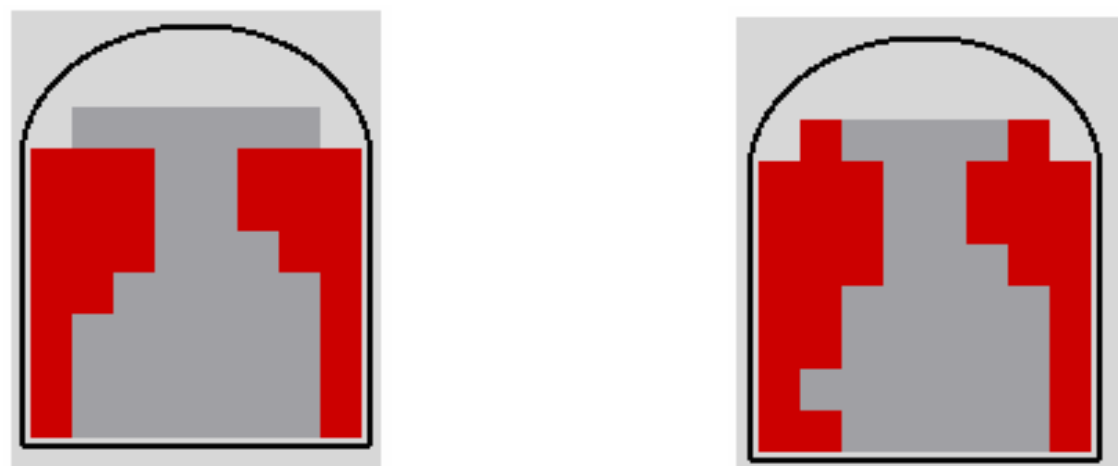

paSSada

paSSada

Duração: $155 \mathrm{~ms}$

Duração: 158ms

$m s \div 20180,4 \mathrm{~A} \div 96 \mathrm{~T} \div 23 \mathrm{P} \div 53$

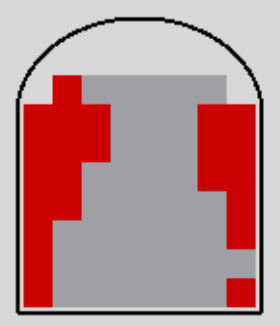

Imagens EPG da fricativa alveolar [s] na posição de ataque de sílaba em palavras trissílabas na posição tônica ( 2 ocorrências de passada e cassada).

paSSava

Duração: $147 \mathrm{~ms}$ 


\section{Anexo 4}
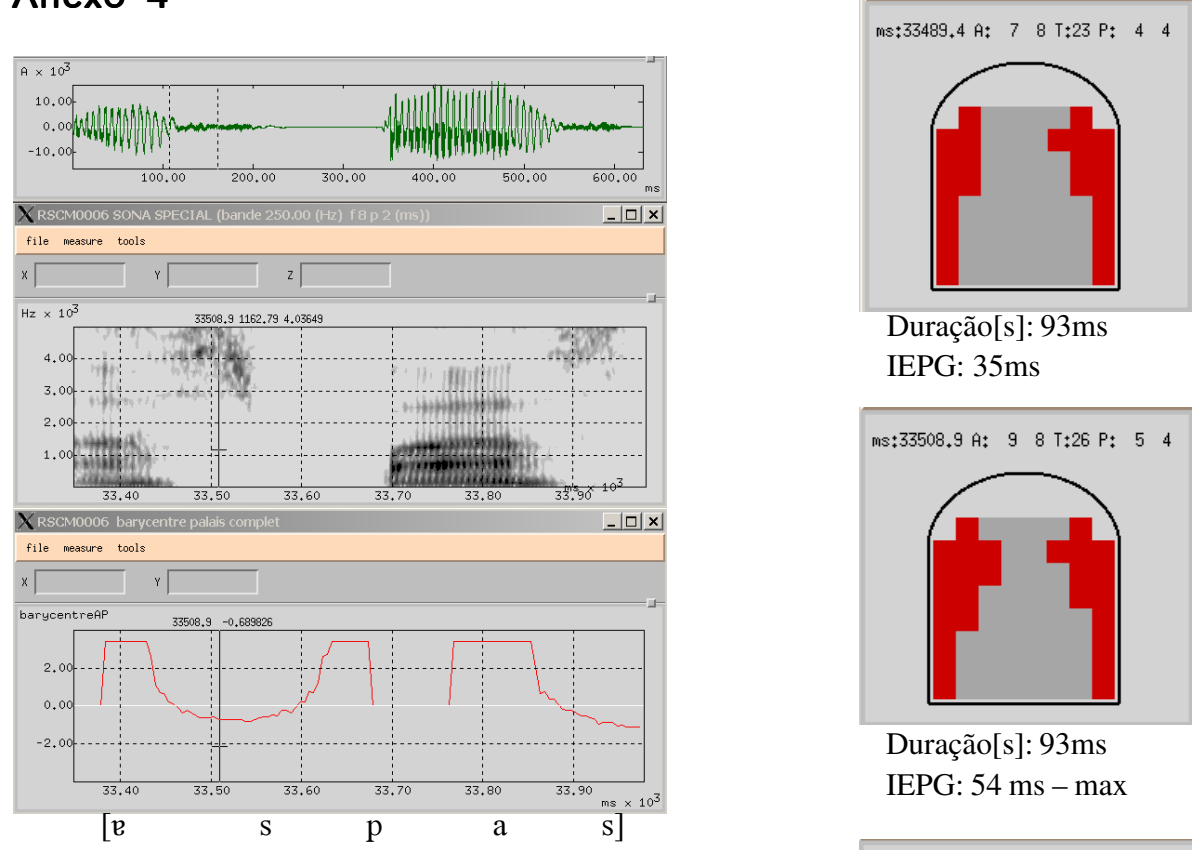

Duração[s]: $93 \mathrm{~ms}$

IEPG: $35 \mathrm{~ms}$

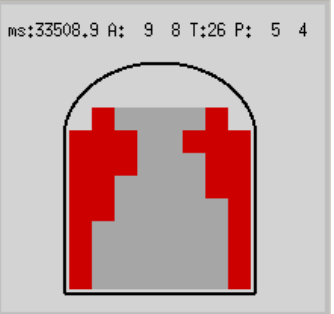

Duração[s]: 93ms

IEPG: $54 \mathrm{~ms}-\max$

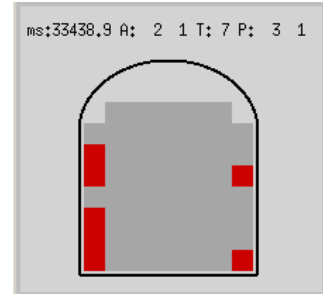

Duração[p]: $93 \mathrm{~ms}$

IEPG: $22 \mathrm{~ms}$

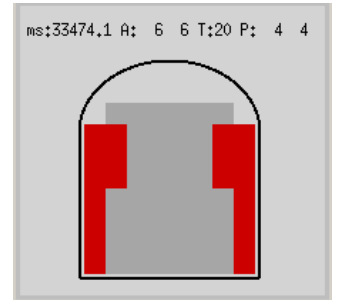

Duração[s]: $93 \mathrm{~ms}$ IEPG: $22 \mathrm{~ms}$

Sinal de fala, espectrograma, baricentro e imagens EPG (IEPG) da seqüência /s p/ em "as pastas", indicando a configuração do contato lingual nos diferentes momentos da produção da fricativa [s], a partir da vogal que precede até o seu desaparecimento no terceiro terço da produção do [p] que se segue.

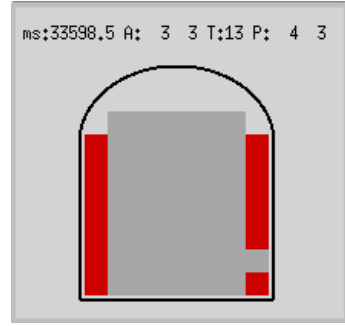

Duração[p]: $149 \mathrm{~ms}$ IEPG: $54 \mathrm{~ms}$

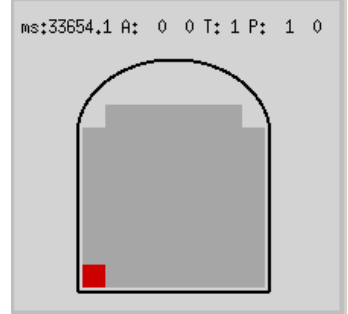

Duração[p]: 149ms IEPG: $107 \mathrm{~ms}$ 


\section{Anexo 5}

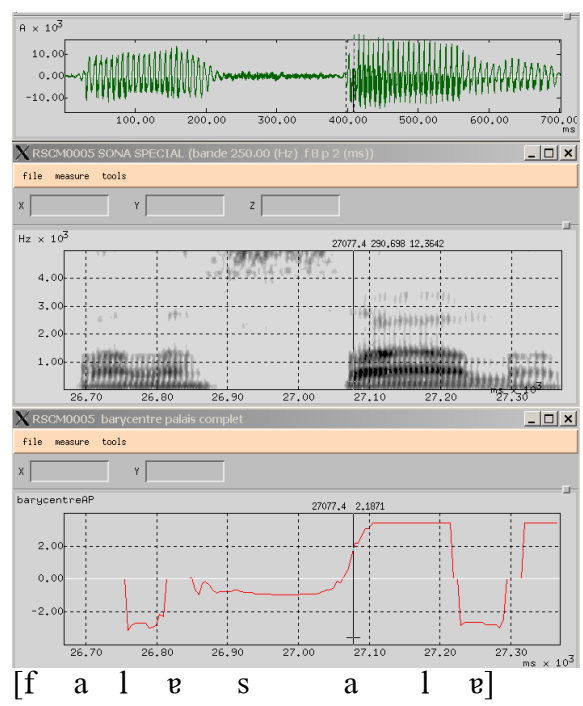

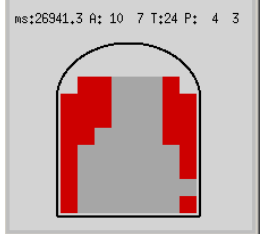

Duração [s]: 190ms IEPG: 66ms

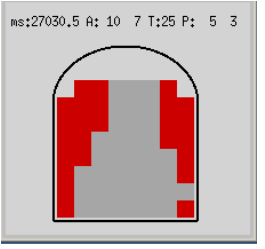

Duração [s]: 190ms IEPG: $153 \mathrm{~ms}$

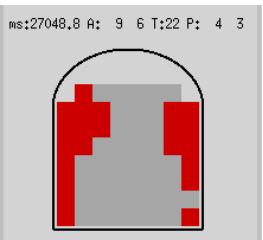

Duração [s]: 190ms IEPG: $170 \mathrm{~ms}$

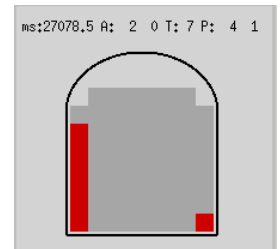

Duração [a]: $162 \mathrm{~ms}$ IEPG: $11 \mathrm{~ms}$

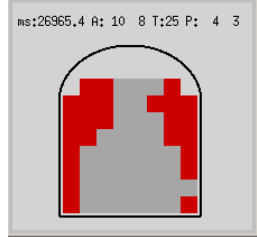

Duração [s]: 190ms IEPG: 90m - max até $153 \mathrm{~ms}$

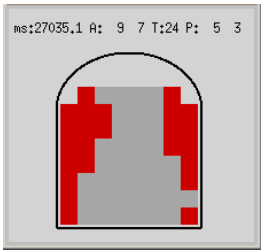

Duração [s]: 190ms IEPG: $160 \mathrm{~ms}$

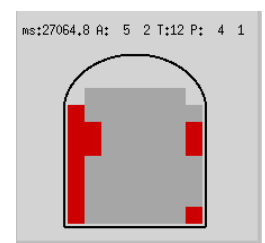

Duração [s]: 190ms IEPG: 190ms

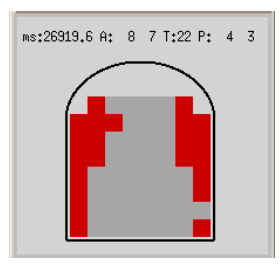

Duração [s]: 190ms IEPG: $42 \mathrm{~ms}$

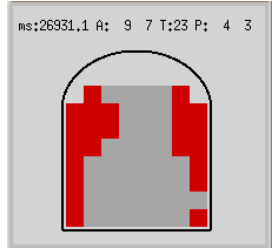

Duração [s]: 190ms IEPG: $55 \mathrm{~ms}$

Sinal de fala, espectrograma, baricentro e imagens EPG (IEPG) da seqüência /s p/ em "fala sala", indicando a configuração do contato lingual nos diferentes momentos da produção da fricativa [s], a partir da vogal que precede até o seu desaparecimento na vogal que se segue. 


\section{Anexo 6}
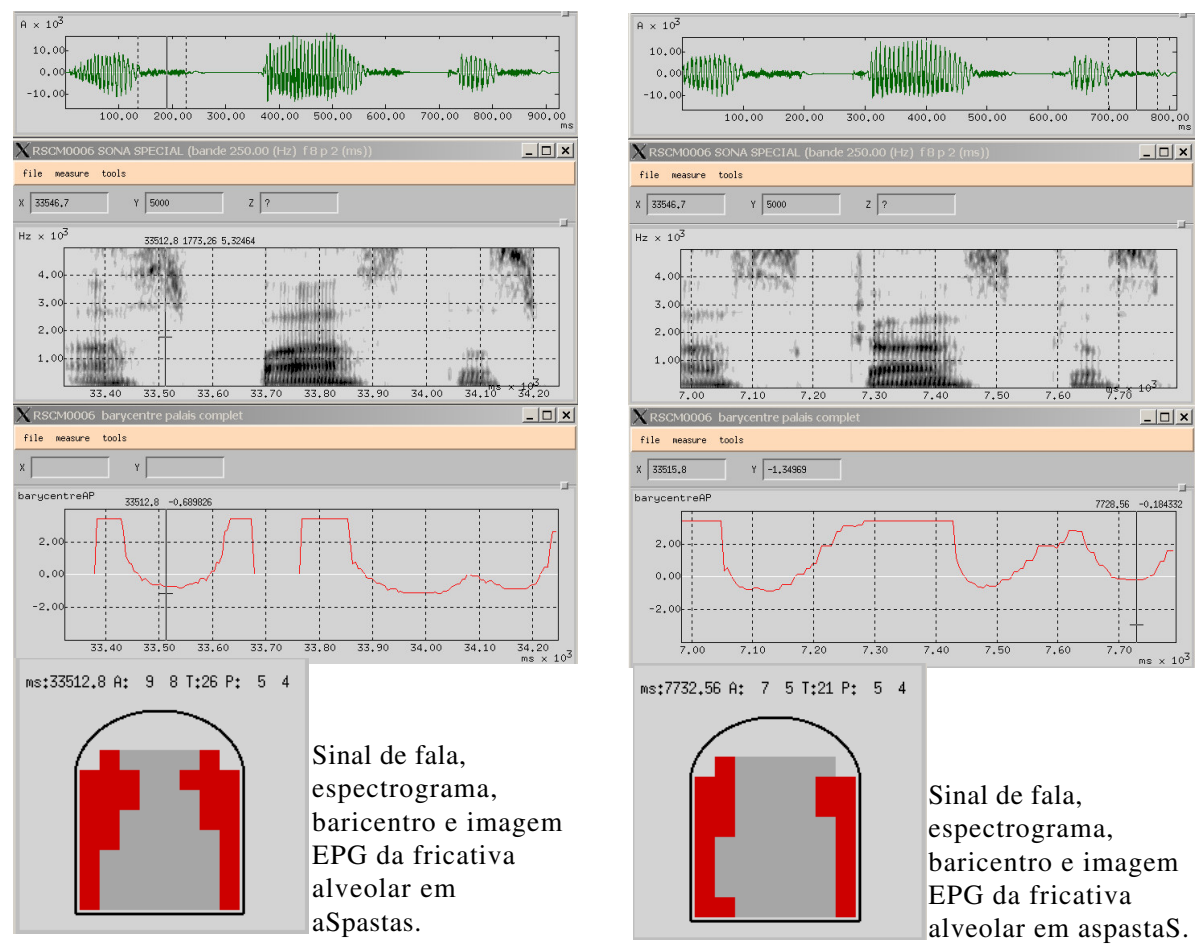

Sinal de fala,
espectrograma,

baricentro e imagem

EPG da fricativa

alveolar em aspastaS.
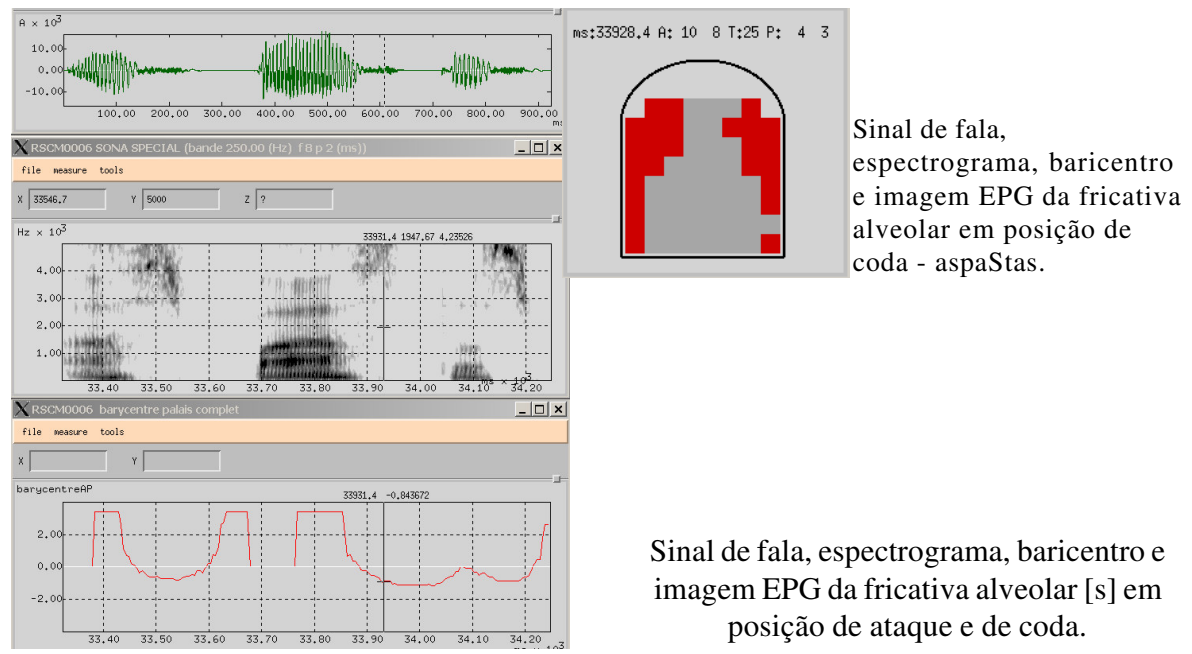

Sinal de fala, espectrograma, baricentro e imagem EPG da fricativa alveolar [s] em posição de ataque e de coda. 


\section{Anexo 7}
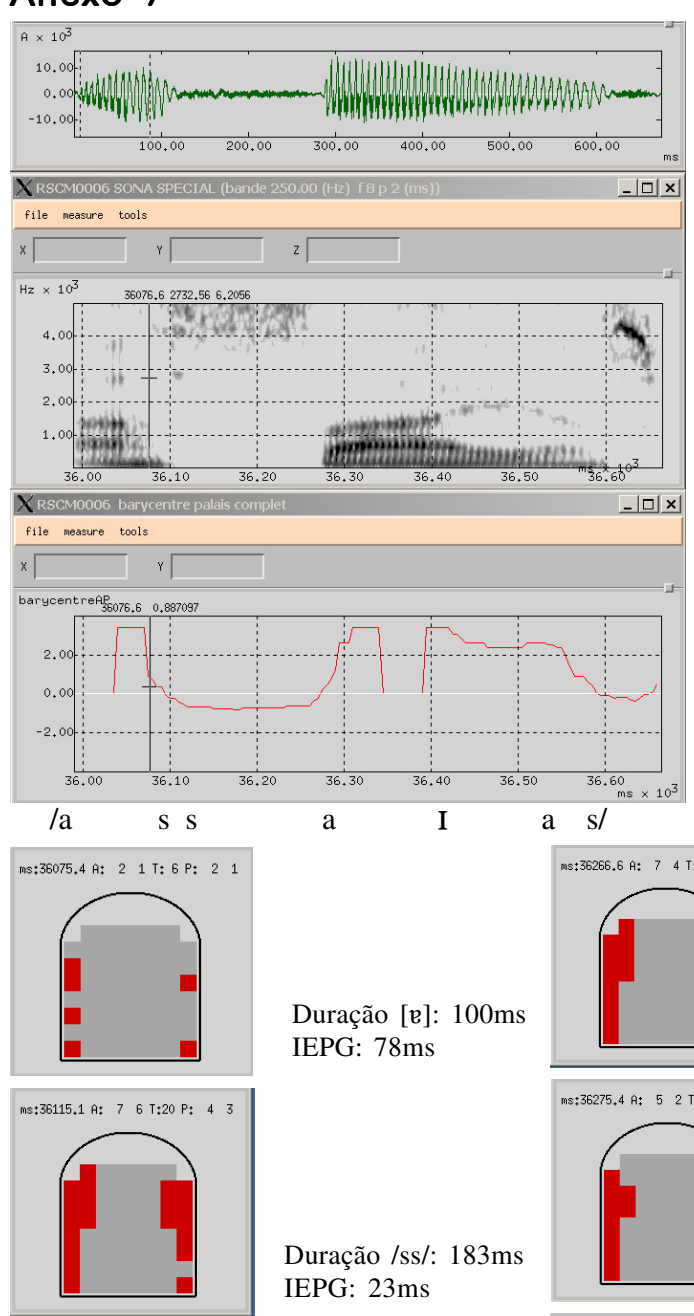

IEPG: $78 \mathrm{~ms}$

raçõo $/ \mathrm{ss} / \cdot 183 \mathrm{~ms}$ IEPG: $23 \mathrm{~ms}$

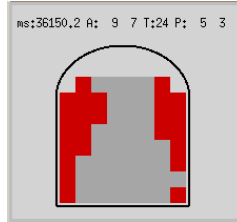
IEPG: $56 \mathrm{~ms}$
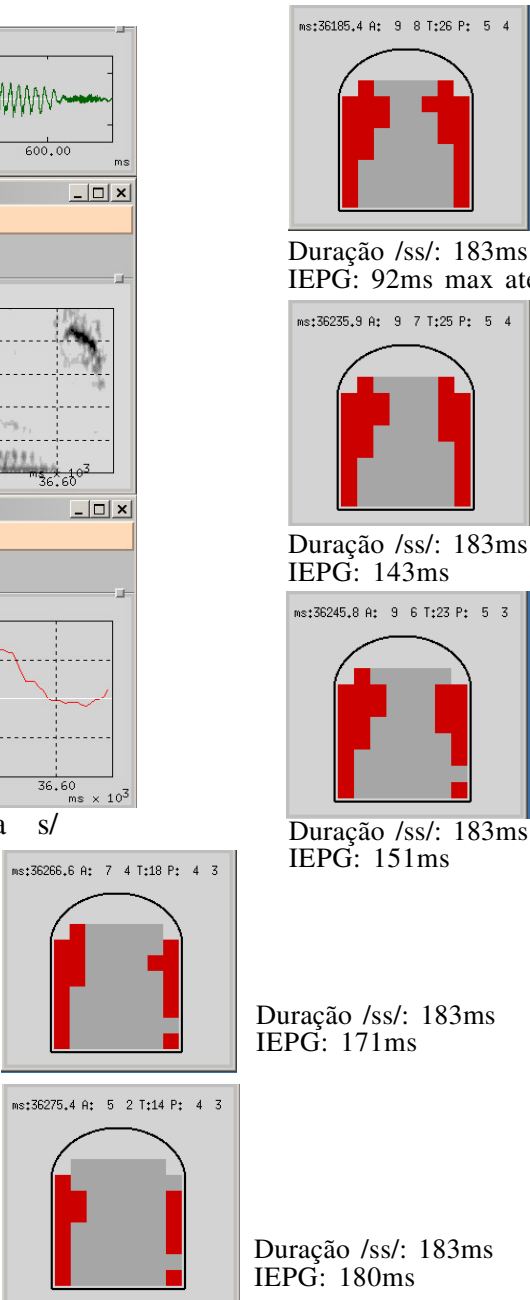

Duração /ss/: $183 \mathrm{~ms}$

IEPG: $92 \mathrm{~ms}$ max até $142 \mathrm{~ms}$

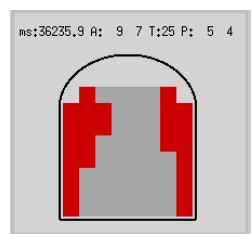

Duração /ss/: $183 \mathrm{~ms}$ IEPG: $143 \mathrm{~ms}$

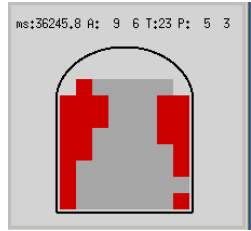

Duração /ss/: $183 \mathrm{~ms}$

IEPG: $151 \mathrm{~ms}$

Duração /ss/: $183 \mathrm{~ms}$ IEPG: $171 \mathrm{~ms}$

Duração /ss/: $183 \mathrm{~ms}$ IEPG: $180 \mathrm{~ms}$

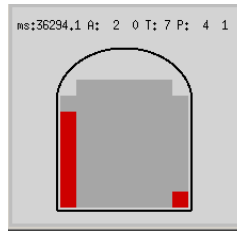

Duração /a/: 133ms IEPG: $18 \mathrm{~ms}$

Sinal de fala, espectrograma, baricentro e imagens EPG (IEPG) da sequiência /s s/ em "as saias", indicando a configuração do contato lingual nos diferentes momentos da produção da fricativa [s], a partir da vogal que precede até o seu desaparecimento na vogal /a/ que se segue. 


\section{Anexo 8}

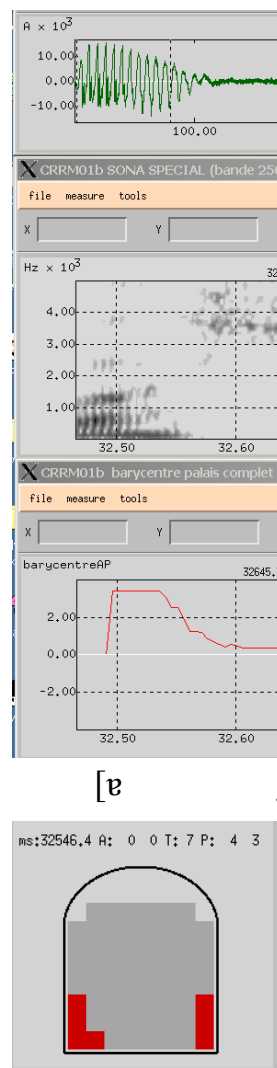

Duração [e]: $86 \mathrm{~ms}$ IEPG: $79 \mathrm{~ms}$

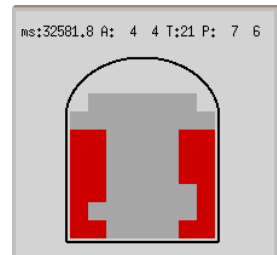

Duração [S]: 180ms IEPG: $29 \mathrm{~ms}$

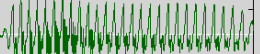
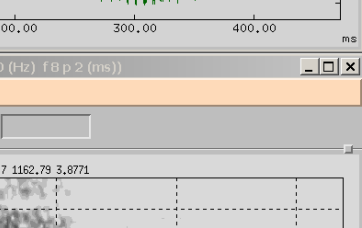

Wast:

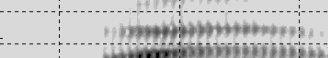
mom.

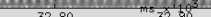

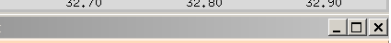
2645.70 .3877097

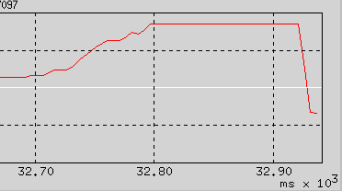
$\int$

a]

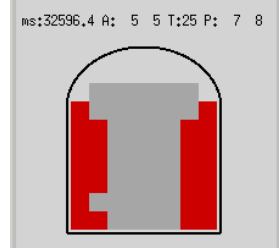

Duração [S]: $180 \mathrm{~ms}$ IEPG: $44 \mathrm{~ms}$

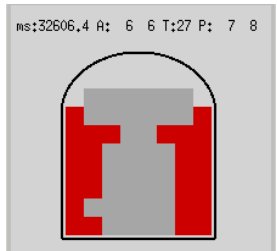

Duração [S]: 180ms IEPG: $55 \mathrm{~ms}$

Sinal de fala, espectrograma, baricentro e imagens EPG da fricativa pós-alveolar [S] da palavra [fe' $\left.\int \mathrm{ded}\right]$
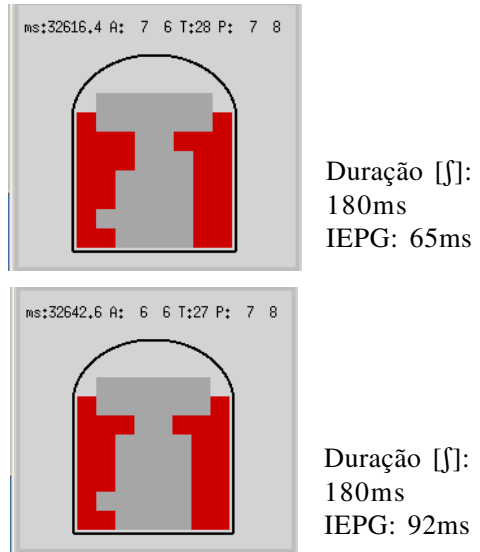

Duração [S]:

$180 \mathrm{~ms}$

IEPG: 92ms

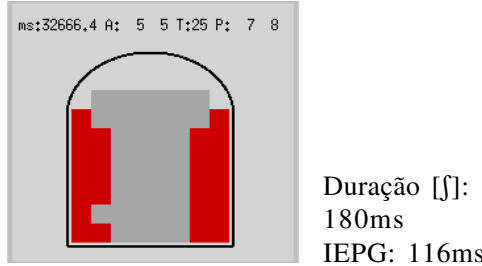

$m s: 32713.4$ A: $\quad 4 \quad 4$ T:23 P: $7 \quad 8$

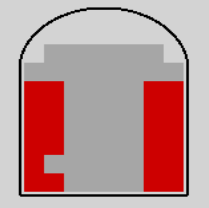

Duração [S]:

$180 \mathrm{~ms}$

IEPG: $160 \mathrm{~ms}$

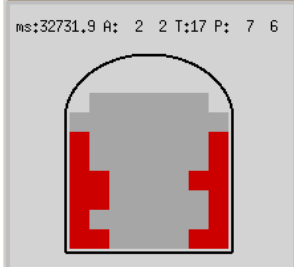

Duração [S]:

$180 \mathrm{~ms}$

IEPG: $178 \mathrm{~ms}$

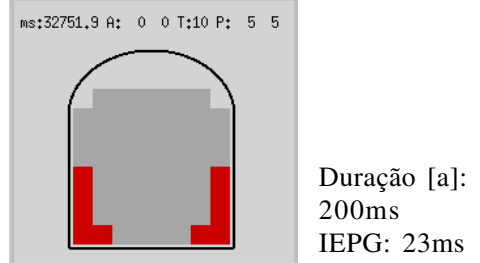




\section{Anexo 9}

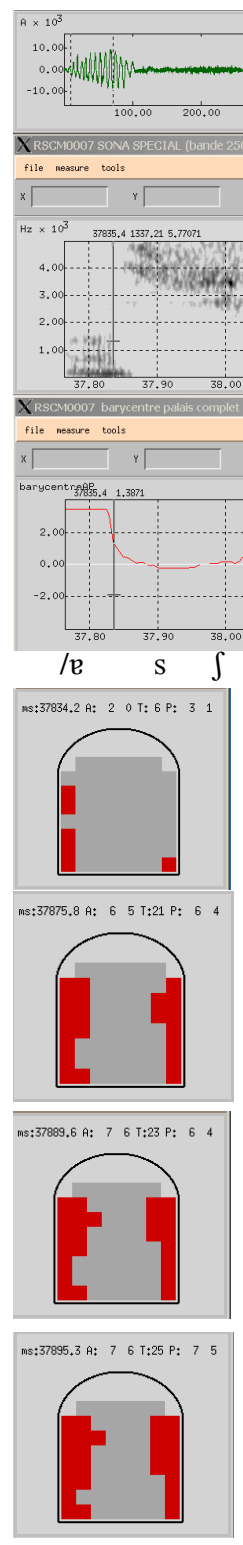

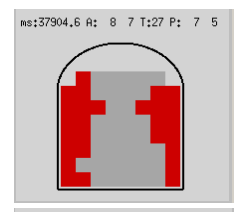
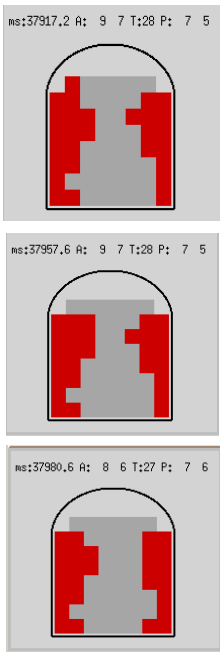

Duração [sf]: $181 \mathrm{~ms}$ IEPG: $119 \mathrm{~ms}$

Duração [sf]: $181 \mathrm{~ms}$ IEPG: $118 \mathrm{~ms}$

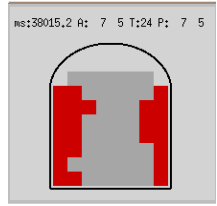

Duração [s]]: $181 \mathrm{~ms}$ IEPG: $156 \mathrm{~ms}$

Duração [s ]]: $181 \mathrm{~ms}$ IEPG: $16 \mathrm{~ms}$

Duração [s]]: $181 \mathrm{~ms}$ IEPG: $28 \mathrm{~ms}$

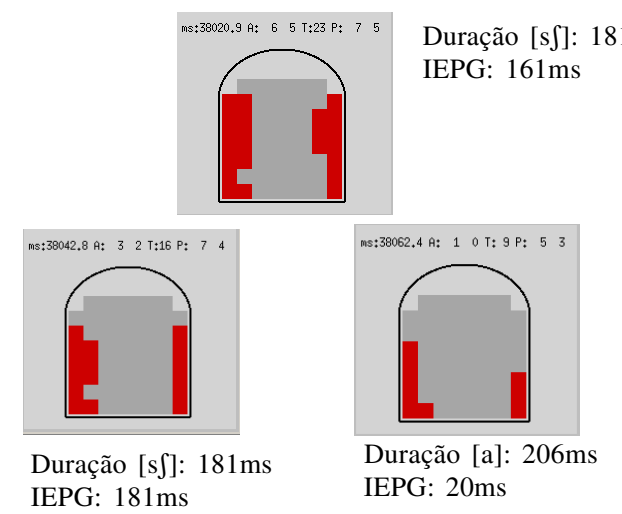

Sinal de fala, espectrograma, baricentro e imagens EPG (IEPG) da seqüência /s $\int /$ em "as chaves", indicando a configuração do contato lingual nos diferentes momentos da produção das fricativas /s $\int /$, a partir da vogal que precede até o seu desaparecimento na vogal /a/ que se segue. 
Anexo 10

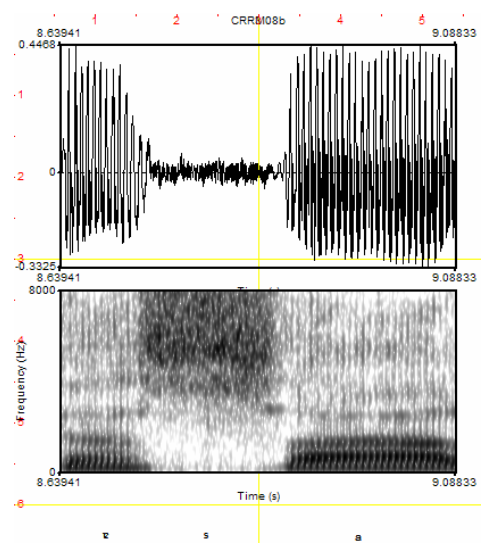

as salas (duração [s] 166ms)

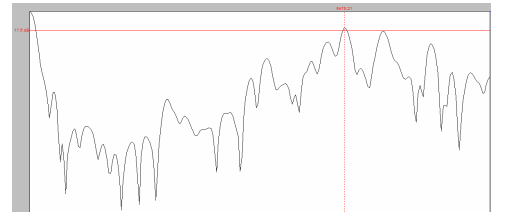

Espectro $(5.475 \mathrm{~Hz} / 18 \mathrm{~dB} /$ slice de $20 \mathrm{~ms})$ no início da fricativa alveolar $(30 \mathrm{~ms})$

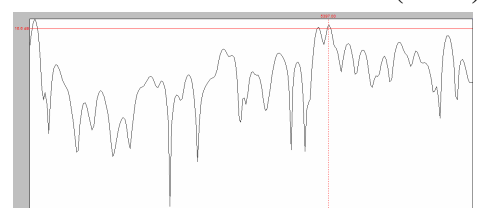

Espectro $(5.397 \mathrm{~Hz} / 17 \mathrm{~dB} / \mathrm{slice}$ de $20 \mathrm{~ms})$ no meio da fricativa alveolar $(50 \mathrm{~ms})$

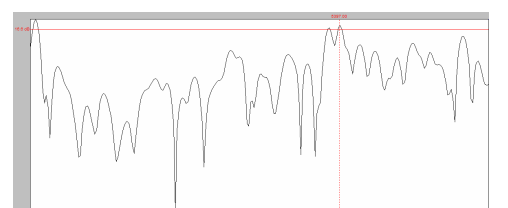

Espectro $(5.141 \mathrm{~Hz} / 18 \mathrm{~dB} /$ slice de $20 \mathrm{~ms})$ no final da fricativa alveolar (70ms)

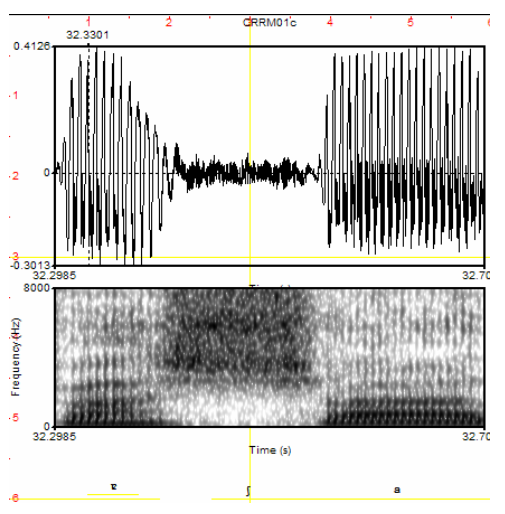

fachada (duração do [S] 189ms)

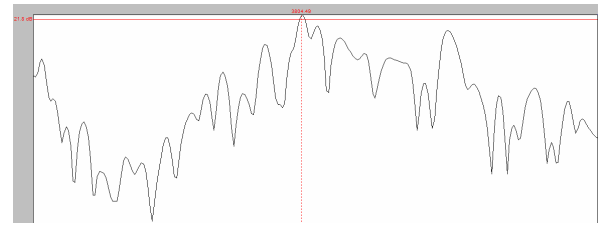

Espectro (3804Hz/21dB/slice de $20 \mathrm{~ms})$ no início da fricativa pós-alveolar (41ms)

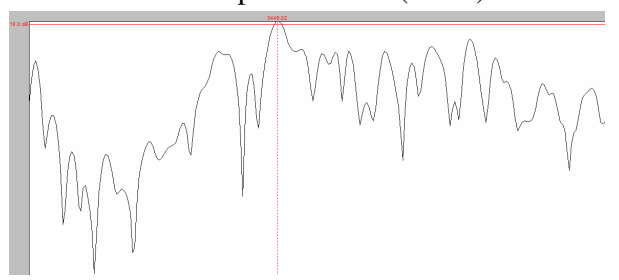

Espectro $(3449 \mathrm{~Hz} / 18 \mathrm{~dB} / \mathrm{slice}$ de $20 \mathrm{~ms})$ no meio da fricativa pós-alveolar $(65 \mathrm{~ms})$

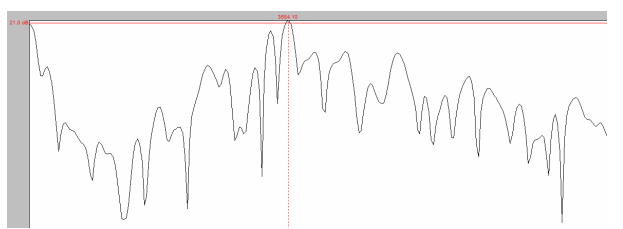

Espectro $(3582 \mathrm{~Hz} / 18 \mathrm{~dB} /$ slice de $20 \mathrm{~ms})$ no final da fricativa pós-alveolar $(115 \mathrm{~ms})$

Sinal de fala, espectrograma e espectro de freqüência da fricativa intervocálica [s] em as salas e em [S] em fachada. 


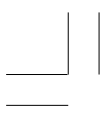

